\title{
Mental health of internally displaced preschool children: a cross-sectional study conducted in Bogotá, Colombia
}

\section{Ilse J. E. Flink, María H. Restrepo, Diana P. Blanco, Mónica M. Ortegon, Carolina L. Enriquez, Tinneke M. J. Beirens, et al.}

Social Psychiatry and Psychiatric Epidemiology

The International Journal for Research in Social and Genetic Epidemiology and Mental Health Services

\section{ISSN 0933-7954}

Soc Psychiatry Psychiatr Epidemiol DOI 10.1007/s00127-012-0611-9
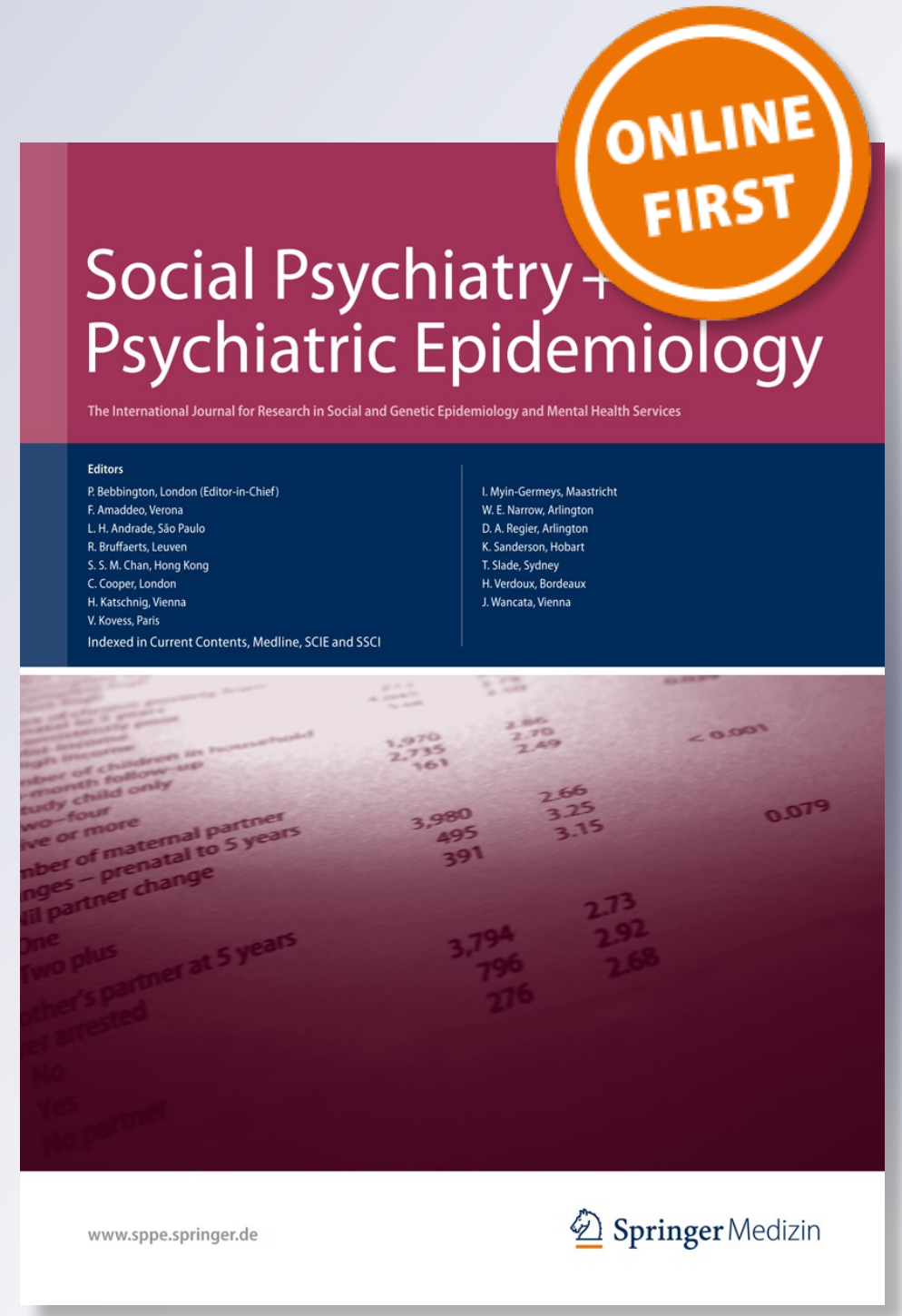

旬 Springer 
Your article is protected by copyright and all rights are held exclusively by SpringerVerlag Berlin Heidelberg. This e-offprint is for personal use only and shall not be selfarchived in electronic repositories. If you wish to self-archive your work, please use the accepted author's version for posting to your own website or your institution's repository. You may further deposit the accepted author's version on a funder's repository at a funder's request, provided it is not made publicly available until 12 months after publication. 


\title{
Mental health of internally displaced preschool children: a cross-sectional study conducted in Bogotá, Colombia
}

\author{
Ilse J. E. Flink • María H. Restrepo • Diana P. Blanco • \\ Mónica M. Ortegon • Carolina L. Enriquez • \\ Tinneke M. J. Beirens • Hein Raat
}

Received: 24 February 2012/ Accepted: 12 October 2012

(C) Springer-Verlag Berlin Heidelberg 2012

\begin{abstract}
Purpose Ongoing armed conflicts, like the one in Colombia, have forcibly displaced millions of people including many young children. This study aimed to assess the mental health of internally displaced preschoolers in Bogotá Colombia and to identify correlates of mental health in these children.

Methods Cross-sectional study conducted among 279 children attending four kindergartens in a deprived neighbourhood in Bogotá. Child mental health was assessed with the Child Behaviour Checklist (CBCL) 1.5-5 years, a parent-report. Univariate analyses and multivariate logistic regressions were performed to assess the association between displacement and child mental health and to identify correlates of mental health in displaced children.

Results Displaced children $(n=90)$ more often met borderline cut-off scores for the CBCL scales than non-displaced children $(n=189)$ (e.g. total problems 46.7 vs. $22.8 \%$; $p<0.001)$. The association between displacement and
\end{abstract}

I. J. E. Flink ( () · T. M. J. Beirens · H. Raat

Department of Public Health, Erasmus University Medical Centre, Room Ae 029, P.O. Box 2040, 3000 CA Rotterdam,

The Netherlands

e-mail: i.flink@erasmusmc.nl

M. H. Restrepo - M. M. Ortegon - C. L. Enriquez Department of Public Health, School of Medicine and Health Sciences, Universidad del Rosario, Bogotá, D.C, Colombia

\section{H. Restrepo}

Interfaculty Doctorate Studies in Public Health,

National University of Colombia, Bogotá, Colombia

D. P. Blanco

Department of Paediatrics, School of Medicine and Health

Sciences, Universidad del Rosario, Bogotá, D.C, Colombia presence of CBCL total problems remained after adjustment for socio-demographic factors (Adjusted OR 3.3, $95 \%$ CI 1.5; 6.9). Caretaker's mental health partly explained the association. In displaced children, caretaker's mental health $(p<0.01)$ and family functioning $(p<0.01)$ were independently associated with child mental health. Exposure to traumatic events and social support was also associated with child mental health; however, associations were not independent. Conclusion In this deprived neighbourhood in Bogotá, preschool children registered as internally displaced presented worse mental health than non-displaced peers. Family functioning and caretaker's mental health were strongly and independently associated with displaced children's mental health.

Keywords Child health - Mental health . Armed conflict · Inequalities · Violence · Poverty

\section{Introduction}

Armed conflicts and wars around the world have forcibly displaced millions of people [1]. The majority are forced to displace within their country or across the border to neighbouring states, with only a small fraction arriving in Western countries to seek asylum [1, 2]. In Colombia, more than four decades of an armed internal conflict have, to date, forcibly displaced at least 3.7 million people (up to $11.6 \%$ of the population), currently making it the country with the largest population of internally displaced in the world [1].

Worldwide, nearly $25 \%$ of the displaced are children [1]. In Colombia, children make up more than $50 \%$ of the internally displaced population [3]. Exposure to wartime trauma can have severe consequences for child mental health also for very young children [4-6]. Two studies 
conducted in the Gaza strip showed that exposure to war-time trauma increased the risk of PTSD symptoms and emotional and behavioural problems in preschoolers $[4,6]$. Research on mental health and forced displacement in children has primarily focused on older refugee children residing in Western countries. Reijneveld et al. [7] and Leavey et al. [8] found levels of emotional and behavioural problems near or above the cut-off in unaccompanied minors and refugees. Other studies found similar results for post-traumatic stress and depression in refugee adolescents [8-10].

Few studies have focused on the psychological effects of forced internal displacement. A study conducted in Nepal among internally displaced adults showed that more than half were suffering from PTSD symptoms and four fifths suffered from anxiety and depressive symptoms [11]. A more recent study conducted in the Jaffna District in Sri Lanka revealed that currently displaced and recently resettled participants were more likely to report symptoms of post-traumatic stress disorder (PTSD) than long-term residents [12]. To our knowledge, no quantitative studies have assessed the impact of forced internal displacement on the mental health of preschool children.

This study sought to address this gap. Our primary objectives were to assess the mental health of preschool children registered as internally displaced and, to compare their mental health to a group of non-displaced peers residing in the same deprived neighbourhood in Bogotá. We hypothesized that displaced children would present worse mental health than non-displaced children. To enhance our understanding of risk and resilience, our secondary objective was to identify correlates of mental health in displaced children.

\section{Methods}

Study design and population

A cross-sectional study was conducted between February and April 2011 in Bogotá, Colombia. Bogotá is the prime receptor municipality for displaced populations [3]. A majority of the displaced in Bogotá live in deprived neighbourhoods. The study was conducted among a convenience sample in the neighbourhood of Kennedy, which has the second largest percentage of internally displaced people in Bogotá [13]. Preschoolers were recruited from four kindergartens that were part of an ongoing collaboration with the Universidad del Rosario which consisted of basic medical check-ups and research activities conducted by medical students. Participating children thus resided in the same neighbourhood (an important indicator of socioeconomic status in Bogotá) and belonged to the same age category. All primary caretakers of preschool children aged
2-6 years attending one of these four kindergartens were invited to participate. The primary caretaker, defined as the person with the greatest responsibility for the daily care of the child, was identified by the teachers.

\section{Study procedure}

The Medical Ethical Review Board of the Universidad del Rosario (Bogotá D.C.) approved the study protocol and consent process. All participants provided their written consent prior to data collection. Data were collected with a questionnaire by a team of 15 , extensively trained, last-semester medical students. As many of the participants had a lower level of education and literacy, the informed consent form and questionnaire were read out to the participants. Participants were also given a copy of the questionnaire and consent form.

\section{Study measures}

\section{Forced internal displacement}

Colombian law defines the internally displaced population as "All persons that have been forced to migrate within their national boundaries, abandoning their actual residence or usual economic activities, because their life, physical integrity, safety or personal freedom are at risk or are directly violated due to one of the following: armed internal conflict, internal tensions or disturbances, generalized violence, massive human rights violations, violations of international humanitarian law or other circumstances that may alter or are altering the public order drastically" [14]. In 1997, law 387 article 32 established the principle that displaced persons (fulfilling the above criteria) have the right to assistance (e.g. schooling, housing and healthcare) [15]. In 2000, a formal National Registry of Displaced Population (Registro Único de Población Desplazada or RUPD) was launched by the government [15]. In this study, children were considered to belong to the displaced group if their families were registered as "internally displaced" by the RUPD. Within the group of displaced children, we further distinguished between first and second generation displaced. If the child was born outside Bogotá, the child was considered first generation displaced. If the child was born in Bogotá, the child was considered second generation displaced.

\section{Child mental health}

The primary caretaker completed the Spanish-Latino version of the Child Behaviour Checklist 1.5-5 years (CBCL/ 1.5-5) [16, 17], a validated parent-report questionnaire that assesses problem behaviour in preschoolers. The CBCL/ 1.5-5 contains 99 problem items rated on a 3-point scale: 0 
(not true), 1 (somewhat or sometimes true) and 2 (very true or often true). By summing the raw scores, seven syndromes (Emotionally Reactive, Anxious/Depressed, Somatic Complaints, Withdrawn, Sleep Problems, Attention Problems and Aggressive Behaviour) can be computed. The internalizing problems score is a summary score for items on the first four syndrome scales and the externalizing problems score is a summary score for attention problems and aggressive behaviour. In this study, scores from the two broadband scales, the total problems scale, which is the sum of all items, and the stress problems scale, a summary score of 7 items and a potential indicator for PTSD in preschoolers are presented [18]. Higher scores indicate greater severity. Good reliability and validity has been reported for the CBCL/1.5-5 [19]. In our study, internal consistencies were good $(\alpha>0.84)$ and only marginally satisfactory for the stress problems scale $(\alpha=0.57)$.

\section{Other measures}

Primary caretaker's mental health The General Health Questionnaire 12 (GHQ12) [20], a measure of mental wellbeing in adults was used to assess caretaker's mental health [21]. Higher scores indicate greater severity. The internal consistency of the GHQ12 in this study was $\alpha=0.76$.

Family functioning The general functioning (GF) scale of the family assessment device (FAD) $[22,23]$ was used to assess family functioning. Higher scores indicate greater severity. The internal consistency of the GF scale in this study was $\alpha=0.82$.

Child exposure to traumatic events since birth We used a checklist of traumatic events which was based on the KiddieSADS PTSD traumatic event checklist [24]. The checklist was adapted to the Colombian context based on expert review. A few displacement-related events specific to the Colombian context (e.g. land mines) were added to the checklist and were based on previous studies on displacement in Colombia [25, 26]. As it may be of particular interest to investigate how aggregate exposure to traumatic events influences child mental health, we used the checklist as an index and categorized it into 0,1 and $>1$ event(s).

Social support The presence of social support was categorized as 'yes' or 'no'. We asked whether the family currently received support (financial or social) from relatives, the church, an NGO, or was receiving any other form of support. If any of these questions were answered positively, the participant was considered to receive some form of social support.
Socio-demographic factors Measures of sociodemographics were based on the 2005 population census conducted by the Colombian National Institute for Statistics [27]. Assessed factors were: child gender; child age; parental age; maternal and paternal educational level defined as: low (no education, primary incomplete, primary complete and secondary incomplete), medium (secondary complete or technical/vocational incomplete) and high (technical/vocational complete or university complete); family income defined as: less than 1 minimum salary monthly in 2011 (approximately 200 Euros), between 1 and 3 minimum salaries monthly, and more than 3 minimum salaries monthly; maternal work (yes/no); type of housing (room, apartment or house) and maternal ethnic descent (European vs. non-European).

Characteristics of the displacement process The assessed characteristics were: time since displacement, categorized into $<1$ year, 1-5 years, 5-10 years and $>10$ years and; main cause of displacement. We asked respondents what the main cause of displacement was by providing them with a list of 14 potential causes (and an 'other' option) identified by previous studies on displacement in Colombia $[25,26]$. Time since displacement was included in the study as a potential correlate of child mental health while cause of displacement was only included as a descriptive.

Statistical analyses

Frequency tables and cross tabulations were used to explore characteristics of the study population (Table 1). Means (SDs) and percentages above borderline cut-off scores were calculated for the CBCL scales, stratified by displacement and generational status (Table 2). CBCL borderline cut-off scores were based on a Peruvian normative sample of children aged 1.5-5 [28]. Logistic regression was used to model the association between displacement and child mental health. A series of models for each CBCL scale was created. Model 1 was the association between displacement and the CBCL scales, adjusted for socio-demographic factors. Only those sociodemographic factors that significantly differed between the non-displaced and displaced group $(p<0.05)$ were entered into the regression model. Considering co-linearity, maternal age $(r=0.42, p<0.001$ with age primary caretaker), paternal age $(r=0.40, p<0.001$ with age primary caretaker), maternal work $(r=0.25, p<0.001$ with maternal educational level) and paternal educational level ( $r=0.50, p<0.001$ with maternal educational level) were not entered. Entered factors were: child gender, child age, primary caretaker's age, maternal education, maternal ethnic descent, family income and housing. In model 2 , we further adjusted for the number of traumatic events the 
child had been exposed to. In model 3; we adjusted for socio-demographic factors and caretaker's mental health. Logistic regression models were also used to examine the association of displacement and family characteristics with mental health in the displaced subgroup (Table 3). We examined the number of events the child had been exposed to, time since displacement, family functioning, caretaker mental health and social support as correlates. To determine whether these correlates were independently associated with child mental health, unadjusted and fully adjusted models were compared.

Statistical analyses were performed using SPSS, version 19 (SPSS Inc., Chicago, IL). A $p$ value $<0.05$ was considered statistically significant.

\section{Results}

Of the 364 approached participants, informed consent was attained from 282 participants (participation rate $77.5 \%$ ). One child was excluded from the analyses because she was older than 6 years. Two other children were excluded because a secondary caretaker, instead of the primary caretaker, completed the questionnaire. Thus, the total sample included 279 children of which 90 were displaced and 189 were non-displaced.

\section{Child and family characteristics}

Table 1 presents the child and family characteristics. Half of the children were boys (52.3\%). Children were 4.2 (SD 1.0) years on average and $59.1 \%$ had been exposed to at least one traumatic event. The primary caretaker/respondent was mostly the mother (71.9\%). Mothers and fathers were, respectively, 30.1 (7.2) and 34.5 (8.2) years on average. $24.6 \%$ of the mothers were single and most had a low educational level (39.7\%). Family income was mostly one to three minimum salaries monthly $(73.7 \%)$, and $49.5 \%$ of the families lived in an apartment. Of the participating families, $41.2 \%$ reported to receive some form of social support.

When stratified by displacement, displaced children were more often male $\left(\chi^{2}=6.7, p=0.01\right)$ and younger $(t \quad 275)=-8.8, p<0.001)$ compared with the nondisplaced group. Displaced and non-Displaced children differed in the number of traumatic events they were exposed to $\left(\chi^{2}=14.9 ; p<0.001\right)$. Compared with the nondisplaced group, displaced families more often belonged to the lowest income group $\left(\chi^{2}=22.3, p<0.001\right)$ were lower educated (maternal education: $\chi^{2}=22.4, p<0.001$ ), more often shared a room than an appartment or a house $\left(\chi^{2}=14.9, p=0.001\right)$, reported poorer family functioning (Mann-Whitney $U=5899.0, p<0.01$ ) and caretaker mental health (Mann-Whitney $U=6062.0, p<0.001$ ). Within the displaced subgroup, $48.9 \%$ of the families were displaced 1 to 5 years ago, and $44.4 \%$ reported that the main cause of their displacement was a threat from an armed group.

\section{Mental health outcomes}

Mean scores on the total problems, the internalizing problems and the externalizing problems scales were significantly higher for displaced children compared to nondisplaced children ( $p<0.05$; Table 2). More caretakers of displaced children reported child problems above the borderline cut-off (Table 2). This was the case for total problems (46.2\% displaced children vs. $22.8 \%$ nondisplaced children, $\left.\chi^{2}=16.4, p<0.001\right)$ and externalizing problems $(30.0 \%$ displaced children vs. $17.5 \%$ non-displaced children $\chi^{2}=5.7, p=0.02$ ).

When stratified by generational status, the mean (SD) in the internalizing and stress problems scales was significantly higher for the first generation displaced children compared to non-displaced children [e.g. mean (SD) internalizing problems: 15.3 (9.3) first generation vs. 11.9 (7.8) non-displaced, $t(231)=1.7, p=0.01]$. This difference was not found for the second generation group. The mean (SD) in the externalizing problems scale was significantly higher for second generation displaced children compared to non-displaced children (externalizing problems mean (SD): 17.0 (8.7) second generation vs. 14.0 (8.3) non-displaced, $t(231)=2.1, p=0.03)$. This difference was not found for the first generation group.

When adjusting for socio-demographic factors (Table 2), differences for the displaced versus the non-displaced group remained significant in the total problems scale [adjuted OR (aOR) 3.3, $95 \%$ CI 1.5; 6.9]. Differences also remained significant for first and second generation displaced versus non-displaced children. When further adjusting for the number of traumatic events the child had been exposed to in model 2, the OR point estimates slightly attenuated in the stress problems scales for the first generation versus the non-displaced group. After adjusting for caretaker's mental health in model 3, the OR point estimates greatly attenuated in all scales for the displaced versus the non-displaced group and particularly for the first generation group. Differences remained significant for the displaced versus non-displaced group in the total problems scale (aOR 2.4, $95 \%$ CI 1.0, 5.4).

Correlates of mental health in displaced children

In unadjusted associations, child exposure to one (OR 2.9, $95 \%$ CI $1.2 ; 7.2$ ) or more than one traumatic event (OR 7.9 , $95 \%$ CI $1.4 ; 42.8)$, poorer mental health of the 
Table 1 Child and family characteristics

\begin{tabular}{|c|c|c|c|c|c|}
\hline & $n$ & $\begin{array}{l}\text { Total sample } \\
(n=279)\end{array}$ & $\begin{array}{l}\text { Non-displaced }(n=189) \\
\text { (reference) }\end{array}$ & $\begin{array}{l}\text { Displaced } \\
(n=90)\end{array}$ & $p$ value $^{\mathrm{a}}$ \\
\hline \multicolumn{6}{|l|}{ Child characteristics } \\
\hline Gender ( $\%$ boys) & 279 & 52.3 & 57.7 & 41.1 & 0.01 \\
\hline Age (years) & 279 & $4.2(1.0)$ & $4.5(0.8)$ & $3.5(1.1)$ & $<0.001$ \\
\hline \multicolumn{6}{|c|}{ Types of traumatic events child has been exposed to ( $\%$ yes) } \\
\hline Murder & 279 & 4.3 & 2.1 & 8.9 & $<0.01$ \\
\hline Torture & 279 & 1.1 & 0.5 & 2.2 & 0.20 \\
\hline Natural disaster & 279 & 38.4 & 44.4 & 25.6 & $<0.01$ \\
\hline Landmines & 279 & 0.7 & 1.1 & 0.0 & 0.33 \\
\hline Sexual abuse & 279 & 7.5 & 6.7 & 7.9 & 0.71 \\
\hline Physical abuse & 279 & 2.9 & 2.1 & 4.4 & 0.23 \\
\hline Domestic violence & 279 & 16.5 & 16.4 & 16.7 & 0.96 \\
\hline \multicolumn{6}{|c|}{ Number of traumatic events child has been exposed to $(\%)$} \\
\hline 0 events & 279 & 35.1 & 29.6 & 46.7 & $<0.001$ \\
\hline 1 event & & 59.1 & 66.7 & 43.3 & \\
\hline$>1$ event & & 5.7 & 3.7 & 10.0 & \\
\hline \multicolumn{6}{|l|}{ Family characteristics } \\
\hline Maternal age (years) & 266 & $30.1(7.2)$ & $31.0(7.2)$ & $28.2(6.9)$ & $<0.01$ \\
\hline Paternal age (years) & 206 & $34.5(8.2)$ & $35.5(8.3)$ & $32.5(7.6)$ & 0.01 \\
\hline Age primary caretaker (years) & 277 & $33.4(11.2)$ & $35.1(10.9)$ & $30.0(10.9)$ & $<0.001$ \\
\hline Maternal ethnic descent (\% non-European) & 268 & 81.7 & 79.7 & 96.5 & $<0.001$ \\
\hline Marital status mother (\% single) & 276 & 24.6 & 26.2 & 21.3 & 0.38 \\
\hline Contact between parents ( $\%$ no) & 277 & 14.1 & 12.2 & 18.0 & 0.20 \\
\hline Primary caretaker ( $\%$ mother) & 278 & 71.7 & 69.7 & 76.7 & 0.23 \\
\hline Educational level mother ${ }^{\mathrm{b}}$ & 277 & & & & $<0.001$ \\
\hline High $(\%)$ & & 14.8 & 19.6 & 4.5 & \\
\hline Medium (\%) & & 39.7 & 43.9 & 30.7 & \\
\hline Low $(\%)$ & & 45.5 & 36.5 & 64.8 & \\
\hline Educational level father ${ }^{b}$ & 250 & & & & $<0.001$ \\
\hline High (\%) & & 14.4 & 18.3 & 6.2 & \\
\hline Medium (\%) & & 30.4 & 36.7 & 17.3 & \\
\hline Low $(\%)$ & & 55.2 & 45.0 & 76.5 & \\
\hline Family income ${ }^{c}$ & 274 & & & & $<0.001$ \\
\hline$>3$ min. salaries $(\%)$ & & 6.6 & 8.6 & 2.3 & \\
\hline 1-3 min. salaries (\%) & & 73.7 & 79.1 & 62.1 & \\
\hline$<1$ min. salary $(\%)$ & & 19.7 & 12.3 & 35.6 & \\
\hline \multicolumn{6}{|l|}{ Work } \\
\hline Mother (\% no) & 275 & 39.4 & 33.0 & 55.2 & $<0.001$ \\
\hline Father (\% no) & 240 & 6.1 & 8.3 & 4.2 & 0.26 \\
\hline Type of housing & 278 & & & & $<0.01$ \\
\hline House $(\%)$ & & 39.1 & 45.0 & 27.0 & \\
\hline Apartment (\%) & & 49.5 & 48.1 & 52.8 & \\
\hline Room (\%) & & 11.1 & 6.9 & 20.2 & \\
\hline Family functioning ${ }^{\mathrm{d}}$ & 277 & $1.0(3.0)$ & $1.5(0.6)$ & $1.9(1.0)$ & $<0.01$ \\
\hline Mental health caretaker ${ }^{\mathrm{d}}$ & 271 & $1.6(0.8)$ & $1.0(3.0)$ & $2.0(3.0)$ & $<0.001$ \\
\hline Presence of social support ( $\%$ yes $)^{\mathrm{e}}$ & 272 & 41.2 & 41.0 & 41.6 & 0.90 \\
\hline \multicolumn{6}{|l|}{ Characteristics of the displacement process } \\
\hline Time since displacement $(\%)$ & 90 & & & & \\
\hline
\end{tabular}


Table 1 continued

\begin{tabular}{|c|c|c|c|c|c|}
\hline & $n$ & $\begin{array}{l}\text { Total sample } \\
(n=279)\end{array}$ & $\begin{array}{l}\text { Non-displaced }(n=189) \\
\text { (reference) }\end{array}$ & $\begin{array}{l}\text { Displaced } \\
(n=90)\end{array}$ & $p$ value $^{\mathrm{a}}$ \\
\hline$>10$ years & & $N A^{f}$ & $N A^{f}$ & 26.7 & $N A^{f}$ \\
\hline $5-10$ years & & $N A^{f}$ & $N A^{f}$ & 15.6 & $N A^{f}$ \\
\hline $1-5$ years & & $N A^{f}$ & $N A^{f}$ & 48.9 & $N A^{f}$ \\
\hline $0-1$ year & & $N A^{f}$ & $N A^{f}$ & 8.9 & $N A^{f}$ \\
\hline \multicolumn{6}{|c|}{ Main cause of displacement } \\
\hline Attack (\% yes) & 90 & $N A^{f}$ & $N A^{f}$ & 23.3 & $N A^{f}$ \\
\hline Threat (\% yes) & 90 & $N A^{f}$ & $N A^{f}$ & 44.4 & $N A^{f}$ \\
\hline Recruitment (\% yes) & 90 & $N A^{f}$ & $N A^{f}$ & 11.1 & $N A^{f}$ \\
\hline Kidnapping (\% yes) & 90 & $N A^{f}$ & $N A^{f}$ & 5.6 & $N A^{f}$ \\
\hline
\end{tabular}

Values are percentages and means (SD)

${ }^{a} p$ values are derived from the $\chi^{2}$ test for categorical variables, the $t$ test for continuous normally distributed variables and the Mann-Whitney $U$ test for non-normally distributed variables comparing displaced children to non-displaced children (reference group)

b High $=$ technical complete, professional incomplete, professional complete, Mid $=$ High school complete and technical incomplete, Low $=$ None, primary school, high school incomplete

${ }^{c}$ Min. salary $= \pm 200$ Euros/month

${ }^{\mathrm{d}}$ Median (IQR)

e Church, family, NGO, other

${ }^{\mathrm{f}}$ Data only applicable for displaced subgroup

caretaker (OR 4.3, $95 \%$ CI 2.0; 9.2) and poorer family functioning (OR 8.4, $95 \%$ CI 3.0; 23.3) were positively associated with scores above the total problems cut-off. The presence of social support was negatively associated with scores above the total problems cut-off (OR 0.4, $95 \%$ CI $0.1,0.8$ ). In the fully adjusted model, caretaker's mental health (aOR 3.4, $95 \%$ CI 1.3; 8.8) and family functioning (aOR 3.9, $95 \%$ CI 1.2 ; 12.7) remained significantly associated with total problems (Table 3 ).

\section{Discussion}

This study showed that children registered as internally displaced presented significantly worse mental health than non-displaced children residing in the same deprived neighbourhood in Bogotá. Primary caretaker's mental health and family functioning were strongly and independently associated with displaced children's mental health.

Compared to a normative sample from Peru, mean scores on CBCL scales were higher in displaced and nondisplaced children which suggest that the children in this study were at a relatively high risk of mental health problems compared to Latin American peers [28]. Displaced children presented worse mental health than nondisplaced children which is in line with related studies conducted among older populations [7, 9, 10]. As also found by others $[6,29]$, caretaker's mental health explained this relationship to a greater extent than child exposure to traumatic events. There may be several explanations for this finding. Firstly, both displaced and non-displaced children in this study resided in a deprived neighbourhood where exposure to violence may be highly prevalent [30]. Secondly, the studied children were very young and in young children maternal proximity to traumatic events has been found to be a better predictor of infant PTSD than child proximity $[6,29]$. It is argued that young children that are exposed to a traumatic event often look for reactions of caregivers as a means of interpreting the threat [31]. In turn, maternal exposure to a traumatic event may influence maternal-child attachment which is of great importance for child mental health [6].

Another interesting finding of this study was that children directly exposed to forced internal displacement (the 1st generation) presented different mental health problems than the 2nd generation. Compared to the non-displaced group, we found that the 1st generation group presented higher scores on the stress and internalizing problem scales while the second generation group presented higher scores on the externalizing problem scales. Though these findings need to be confirmed by research with larger samples of children, this may indicate that the impact of forced internal displacement unfolds differently in preschoolers that are directly and indirectly exposed to the event. Alongside the mental health differences, it is of interest that both generational groups presented significantly more problem behaviour than unexposed children. This implies that preschoolers that were not directly exposed to forced internal displacement are nonetheless impacted by the event; there is a so-called 'intergenerational risk'. This is in 
Table 2 Univariate and multivariate analyses of the association between forced internal displacement and child mental health $(n=279)$

\begin{tabular}{|c|c|c|c|c|c|c|c|c|c|c|c|}
\hline $\begin{array}{l}\text { CBCL/1.5-5 } \\
\text { scales }\end{array}$ & $n$ & $\begin{array}{l}\text { Mean } \\
\text { scale } \\
\text { score (SD) }\end{array}$ & $p$ value $^{\mathrm{a}}$ & $\begin{array}{l}\text { Above } \\
\text { cut-off } \\
(\%)^{\text {b }}\end{array}$ & $p$ value ${ }^{\mathrm{c}}$ & $\begin{array}{l}\text { Adjusted } \\
\text { model } 1^{\mathrm{d}} \\
\text { OR }(95 \% \text { CI })\end{array}$ & $p$ value $\mathrm{e}^{\mathrm{e}}$ & $\begin{array}{l}\text { Adjusted } \\
\text { Model } 2^{\mathrm{d}} \\
\text { OR }(95 \% \text { CI })\end{array}$ & $p$ value $\mathrm{e}^{\mathrm{e}}$ & $\begin{array}{l}\text { Adjusted } \\
\text { model } 3^{\mathrm{d}} \\
\text { OR }(95 \% \mathrm{CI})\end{array}$ & $p$ value $^{\mathrm{e}}$ \\
\hline \multicolumn{12}{|l|}{ Total problems } \\
\hline $\begin{array}{l}\text { Non-displaced } \\
\text { (reference) }\end{array}$ & 189 & $40.8(20.8)$ & & 22.8 & & $\begin{array}{l}1.0 \\
\text { (reference) }\end{array}$ & & $\begin{array}{l}1.0 \\
\quad \text { (reference) }\end{array}$ & & $\begin{array}{l}1.0 \\
\quad \text { (reference) }\end{array}$ & \\
\hline Displaced & 90 & $49.2(23.3)$ & $<0.01$ & 46.7 & $<0.001$ & $3.3(1.5 ; 6.9)$ & $<0.01$ & $3.4(1.6 ; 7.3)$ & $<0.01$ & $2.4(1.0 ; 5.4)$ & 0.04 \\
\hline 1st generation & 44 & $50.0(23.3)$ & 0.01 & 47.7 & $<0.01$ & $3.9(1.6 ; 9.1)$ & $<0.01$ & $4.0(1.7 ; 9.6)$ & $<0.01$ & $2.2(0.9 ; 5.7)$ & 0.10 \\
\hline 2nd generation & 44 & $48.9(24.0)$ & 0.03 & 47.7 & $<0.01$ & $2.7(1.1 ; 6.7)$ & 0.04 & $2.8(1.1 ; 7.1)$ & 0.02 & $2.6(0.9 ; 7.1)$ & 0.07 \\
\hline \multicolumn{12}{|c|}{ Internalizing problems } \\
\hline $\begin{array}{l}\text { Non-displaced } \\
\quad(\text { ref })\end{array}$ & 189 & $11.9(7.8)$ & & 30.7 & & $\begin{array}{l}1.0 \\
\quad \text { (reference) }\end{array}$ & & $\begin{array}{l}1.0 \\
\quad \text { (reference) }\end{array}$ & & $\begin{array}{l}1.0 \\
\quad \text { (reference) }\end{array}$ & \\
\hline Displaced & 90 & $14.4(9.3)$ & 0.02 & 36.7 & 0.32 & $1.3(0.6 ; 2.7)$ & 0.50 & $1.3(0.6 ; 2.8)$ & 0.58 & $0.9(0.4 ; 1.9)$ & 0.72 \\
\hline 1st generation & 44 & $15.3(9.3)$ & 0.01 & 40.9 & 0.19 & $1.8(0.8 ; 4.1)$ & 0.16 & $1.8(0.8 ; 4.3)$ & 0.16 & $1.0(0.4 ; 2.6)$ & 0.92 \\
\hline 2nd generation & 44 & $13.7(9.7)$ & 0.19 & 34.1 & 0.66 & $0.9(0.3 ; 2.1)$ & 0.74 & $0.9(0.4 ; 2.2)$ & 0.86 & $0.7(0.2 ; 1.8)$ & 0.43 \\
\hline \multicolumn{12}{|c|}{ Externalizing problems } \\
\hline $\begin{array}{l}\text { Non-displaced } \\
\text { (reference) }\end{array}$ & 189 & $14.0(8.3)$ & & 17.5 & & $\begin{array}{l}1.0 \\
\text { (reference) }\end{array}$ & & $\begin{array}{l}1.0 \\
\quad \text { (reference) }\end{array}$ & & $\begin{array}{l}1.0 \\
\quad \text { (reference) }\end{array}$ & \\
\hline Displaced & 90 & $16.9(8.5)$ & $<0.01$ & 30.0 & 0.02 & $2.0(0.9 ; 4.6)$ & 0.10 & $2.1(0.9 ; 4.9)$ & 0.10 & $1.4(0.6 ; 3.4)$ & 0.40 \\
\hline 1st generation & 44 & $16.8(8.6)$ & 0.05 & 25.0 & 0.25 & $1.8(0.7 ; 4.7)$ & 0.22 & $2.0(0.7 ; 5.1)$ & 0.17 & $1.1(0.4 ; 2.9)$ & 0.91 \\
\hline 2nd generation & 44 & $17.0(8.7)$ & 0.03 & 36.4 & $<0.01$ & $2.3(0.8 ; 6.2)$ & 0.10 & $2.4(0.9 ; 6.6)$ & 0.08 & $2.1(0.7 ; 6.1)$ & 0.16 \\
\hline \multicolumn{12}{|l|}{ Stress problems } \\
\hline $\begin{array}{l}\text { Non-displaced } \\
\quad \text { (ref) }\end{array}$ & 189 & $2.7(2.2)$ & & 12.7 & & $\begin{array}{l}1.0 \\
\quad \text { (reference) }\end{array}$ & & $\begin{array}{l}1.0 \\
\quad \text { (reference) }\end{array}$ & & $\begin{array}{l}1.0 \\
\quad \text { (reference) }\end{array}$ & \\
\hline Displaced & 90 & $3.3(2.6)$ & 0.05 & 17.8 & 0.26 & $1.7(0.6 ; 4.5)$ & 0.29 & $1.7(0.6 ; 4.5)$ & 0.34 & $1.3(0.5 ; 3.5)$ & 0.61 \\
\hline 1st generation & 44 & $3.6(2.6)$ & 0.02 & 22.7 & 0.09 & $2.4(0.8 ; 7.0)$ & 0.10 & $2.3(0.8 ; 6.8)$ & 0.61 & $1.6(0.5 ; 4.8)$ & 0.41 \\
\hline 2nd generation & 44 & $3.1(2.7)$ & 0.33 & 13.6 & 0.87 & $1.0(0.3 ; 3.5)$ & 0.99 & $1.1(0.3 ; 3.8)$ & 0.22 & $1.0(0.3 ; 3.5)$ & 0.95 \\
\hline
\end{tabular}

$C B C L$ Child Behaviour Checklist, $C I$ confidence intervals, $S D$ standard deviations

${ }^{a} p$ values are derived from $t$ tests for displaced compared to non-displaced group and 1st (born outside Bogotá) and 2nd generation (born in Bogotá) displaced compared to non-displaced group

b $\%$ refers to the percentage of sample at or above cut-off score: total problems $=52$; internalizing problems $=14$; externalizing problems $=21$; stress problems $=5$ )

c $p$ values are derived from $\chi^{2}$ tests

d Covariates in the adjusted model 1: child gender, child age, caretaker age, maternal education, income, type of housing and maternal ethnic descent; covariates in the adjusted model 2: child gender, child age, caretaker age, maternal education, income, type of housing, maternal ethnic descent and number of traumatic events child has been exposed to; covariates in the adjusted model 3: child gender, child age, caretaker age, maternal education, income, type of housing, maternal ethnic descent and mental health of caretaker

e $p$ values are based on empirical standard error estimates from logistic regression models

line with different studies on the intergenerational effects of war-related trauma on child mental health [32]. These studies have shown that, among other factors, ambivalent attachment styles [33], violent and/or stressful family atmosphere and communication patterns (from silence to over disclosure) can explain how trauma can be transmitted from one generation to the other [32].

To enhance our understanding of risk and resilience, we evaluated correlates of displaced children's mental health. We found that primary caretaker's mental health and family functioning were independently associated with displaced children's mental health. As noted by Betancourt and Khan [34], the family can influence the mental health of war-affected children in two ways: either the family forms a 'protective shield' against hardship or a child's management of war-stress is complicated because parents or the family do not have the capacity to effectively manage stress. In preschool children, the influence of the family on child well-being may be even larger as the family is often their main frame of reference [35].

In unadjusted analyses, we found that child exposure to more than one traumatic event was more strongly associated with mental health problems than exposure to a single traumatic event. In a study by Kohrt et al. [36] aggregate traumatic exposure, rather than single traumatic events, was associated with poor mental health in former child soldiers. Lastly, our study indicated that although social support was associated with mental health problems in 
Table 3 Correlates of mental health in displaced children $(n=90)$

\begin{tabular}{|c|c|c|c|c|}
\hline Correlates & Unadjusted OR (95 \% CI) & $p$ value & Adjusted $\mathrm{OR}^{\mathrm{a}}(95 \% \mathrm{CI})$ & $p$ value \\
\hline \multicolumn{5}{|l|}{ Child exposure to traumatic events } \\
\hline 0 events & 1.0 (reference) & & 1.0 (reference) & \\
\hline 1 event & $2.9(1.2 ; 7.2)$ & 0.02 & $2.0(0.6 ; 6.5)$ & 0.23 \\
\hline$>1$ events & $7.9(1.4 ; 42.8)$ & 0.02 & $1.9(0.2 ; 15.1)$ & 0.53 \\
\hline \multicolumn{5}{|l|}{ Time since displacement } \\
\hline$>10$ years & 1.0 (reference) & & 1.0 (reference) & \\
\hline $5-10$ years & $1.1(0.3 ; 4.1)$ & 0.87 & $3.0(0.3 ; 31.8)$ & 0.36 \\
\hline $1-5$ years & $1.1(0.4 ; 3.0)$ & 0.90 & $3.1(0.3 ; 36.2)$ & 0.36 \\
\hline$<1$ year & $0.4(0.1 ; 2.2)$ & 0.30 & $1.9(0.2 ; 16.2)$ & 0.55 \\
\hline Mental health of primary caretaker & $4.3(2.0 ; 9.2)$ & $<0.001$ & $3.4(1.3 ; 8.8)$ & 0.01 \\
\hline Family functioning & $8.4(3.0 ; 23.3)$ & $<0.001$ & $3.9(1.2 ; 12.7)$ & 0.02 \\
\hline \multicolumn{5}{|l|}{ Presence of social support } \\
\hline No & 1.0 (reference) & & 1.0 (reference) & \\
\hline Yes & $0.4(0.1 ; 0.8)$ & 0.02 & $0.6(0.2 ; 1.6)$ & 0.28 \\
\hline
\end{tabular}

$C B C L$ Child Behaviour Checklist, $C I$ confidence intervals, $N G O$ non-governmental organization

a Adjusted model includes all correlates: time since displacement, number of traumatic events, mental health of primary caretaker, family functioning and the presence of social support

displaced children, the association was not independent. It is likely that families that function better and caretakers with better mental health are also more likely to seek social support, hence explaining the lack of association in the fully adjusted model [34].

Some methodological issues need to be considered. First, this study was cross-sectional in design implying that the identified correlates of mental health in displaced children can not be referred to as risk or protective factors as we are unable to determine a causal effect [37]. The CBCL/1.5-5 is a parent-report questionnaire and the possibility of information bias might be present. To address this issue, we adjusted for caretaker's/respondent's mental health and other family variables. Although these variables mediated some of the effect, differences between displaced and non-displaced children remained significant for the total problems scale. We were unable to use standardized instruments for assessing social support and trauma exposure due to questionnaire length restrictions and/or the lack of available instruments for very young children. This may limit our findings with regard to the importance of social support and traumatic events for the mental health of displaced preschoolers. Furthermore, the stress problems scale of the CBCL/1.5-5 had a marginally satisfactory internal consistency in our sample. Hence, findings for this scale should be interpreted cautiously and further research on the reliability of this scale is necessary.

Defining the displacement status according to government registration limits the generalizability of this study. Approximately $23 \%$ of the displaced in Colombia do not register themselves, due to lack of knowledge or fear [3]. As the benefits of registration have been associated with better mental health in war-exposed children [34], differences between displaced and non-displaced children may have been larger if unregistered displaced children had also been included. It should furthermore be noted that only school-going children were included in this study. Consequently, findings may not be generalizable to 2-6 year olds that do not attend kindergartens (approximately $33 \%$ of the population in Bogotá [38]).

This study is the first to quantify the impact of forced internal displacement on preschool children's mental health. To further elucidate this impact, longitudinal population-based research including multiple respondents (i.e. teachers, children, caregivers and parents) is desired. Also, in-depth qualitative studies are needed to document the changes that families go through after being forcibly displaced due to an armed internal conflict. This information can be used to gain a better understanding of how forced internal displacement affects preschoolers and their families. Considering this study's findings, we recommend interventions that focus on building family skills for coping with forced internal displacement. This is likely to benefit child mental health and caretaker's mental health. In addition, it is of importance to also be attentive to intergenerational transmission of war-related trauma in internally displaced children and also include indirectly exposed children in interventions targeted at enhancing the mental health of displaced families.

Acknowledgments We thank Aura Hernandez and Armando Steven Prieto from Universidad del Rosario, for helping with the study administration. Our appreciation also goes out to the team of students from Universidad del Rosario for helping with the data collection and the teaching staff for their collaboration. Lastly, we would like to thank 
Professor Frank Verhulst (Erasmus University Medical Centre, Rotterdam, The Netherlands) for his suggestions on the manuscript and study design and Professor Thomas Achenbach (University of Vermont, BT, United States) for his suggestions on the administration of the CBCL/ 1.5-5 in Colombia. The Erasmus Mundus Program of the European Union provided the primary author with a grant to cover living and travel costs in Colombia. All costs related the design of the study, data collection, data management, analysis, interpretation, manuscript preparation, and manuscript review were covered by the Erasmus University Medical Centre and Universidad del Rosario.

Conflict of interest The authors declare that they have no conflict of interest.

\section{References}

1. UNHCR (2007) Global trends: refugees, asylum-seekers, returnees, internally displaced and stateless persons, vol 2011. United Nations High Commissioner for Refugees, Geneva

2. UNHCR (2006) The state of the world's refugees 2006-Human displacement in the new millenium. United Nations High Commissioner for Refugees, Geneva

3. IDMC (2011) Colombia: Property restitution in sight but integration still distant. Internal Displacement Monitoring Center, Geneva

4. Thabet AA, Karim K, Vostanis P (2006) Trauma exposure in preschool children in a war zone. Br J Psychiatry 188:154-158

5. Jensen PS, Shaw J (1993) Children as victims of war: current knowledge and future research needs. J Am Acad Child Adolesc Psychiatry 32(4):697-708

6. Feldman R, Vengrober A (2011) Posttraumatic stress disorder in infants and young children exposed to war-related trauma. J Am Acad Child Adolesc Psychiatry 50(7):645-658

7. Reijneveld SA, de Boer JB, Bean T, Korfker DG (2005) Unaccompanied adolescents seeking asylum: poorer mental health under a restrictive reception. J Nerv Ment Dis 193(11):759-761

8. Leavey G, Hollins K, King M, Barnes J, Papadopoulos C, Grayson K (2004) Psychological disorder amongst refugee and migrant schoolchildren in London. Soc Psychiatry Psychiatr Epidemiol 39(3):191-195

9. Halcon LL, Robertson CL, Savik K, Johnson DR, Spring MA, Butcher JN, Westermeyer JJ, Jaranson JM (2004) Trauma and coping in Somali and Oromo refugee youth. J Adolesc Health 35(1): 17-25

10. Hodes M, Jagdev D, Chandra N, Cunniff A (2008) Risk and resilience for psychological distress amongst unaccompanied asylum seeking adolescents. J Child Psychol Psychiatry 49(7): 723-732

11. Thapa SB, Hauff E (2005) Psychological distress among displaced persons during an armed conflict in Nepal. Soc Psychiatry Psychiatr Epidemiol 40(8):672-679

12. Husain F, Anderson M, Lopes Cardozo B, Becknell K, Blanton C, Araki D, Vithana EK (2011) Prevalence of war-related mental health conditions and association with displacement status in postwar Jaffna District, Sri Lanka. JAMA 306(5):522-531

13. Secretaria de la hacienda (2004) [Route through Kennedy. Physical and socio-economic diagnosis of the neighbourhoods in Bogotá]. Diagnostico Físico y socio-economico de las localidades de Bogotá. Secretaria de la hacienda, Bogotá

14. Lozano M, Gomez M (2004) [Psychological, social and juridical aspects of forced internal displacement in Colombia] Aspectos psicológicos, sociales y jurídicos del desplazamiento forzoso en Colombia Acta colombiana de psicología 12:103-119
15. Constitutional Court of Colombia (2004) [Statement $\mathrm{N}^{\circ} \mathrm{T}-025$ of 2004]. Sentencia $\mathrm{N}^{\circ} \mathrm{T}-025$ de 2004. Constitutional Court of Colombia, Bogotá

16. Achenbach T, Rescorla L (2000) Manual for the ASEBA Preschool Forms \& Profiles. University of Vermont, Research Center for Children, Youths \& Families, Burlington

17. Rubio-Stipec M, Bird H, Canino G, Gould M (1990) The internal consistency and concurrent validity of a Spanish translation of the Child Behavior Checklist. J Abnorm Child Psychol 18(4):393-406

18. Dehon C, Scheeringa MS (2006) Screening for preschool posttraumatic stress disorder with the Child Behavior Checklist. J Pediatr Psychol 31(4):431-435

19. Achenbach T, Rescorla L (2000) Manual for the ASEBA Preschool Forms and Profiles. University of Vermont: Research Center for Children, Youth, \& Families, Burlington

20. Munoz PE, Vazquez JL, Rodriguez Insausti F, Pastrana E, Varo J (1979) [Spanish adaptation of the General Health Questionnaire (G.H.Q.) of D. P. Goldberg (a method for identifying psychiatric cases in the community)] Adaptacion espanola del General Health Questionnaire (G.H.Q.) de D. P. Goldberg (un metodo de identificacion de casos psiquiatricos en la comunidad. Arch Neurobiol (Madr) 42 (2):139-158

21. Goldberg DP (1978) Manual of the General Health Questionnaire. NFER Publishing, Windsor

22. Barroilhet S, Cano-Prous A, Cervera-Enguix S, Forjaz MJ, Guillen-Grima F (2009) A Spanish version of the Family Assessment Device. Soc Psychiatry Psychiatr Epidemiol 44(12):1051-1065

23. Byles J, Byrne C, Boyle MH, Offord DR (1988) Ontario Child Health Study: reliability and validity of the general functioning subscale of the McMaster Family Assessment Device. Fam Process 27(1):97-104

24. Kaufman J, Chambers W, Pulg-Antich J, Birmaher B, Rao U, Ryan ND (1996) Kiddie-SADS-Present and Lifetime Version. University of Pittsburgh, Pittsburg

25. IDMC (2009) Colombia: New displacement continues, response still ineffective. Internal Displacement Monitoring Center, Norwegian Refugee Council, Norway

26. Salamanca L, Gómez F (2009) Rasgos caracteristicos del desplazamiento. In: El reto ante la tragedia humanitaria del desplazamiento forzado: Superar la exclusión social de la población desplazada, vol 3. Comisión de Seguimiento a la Política Pública sobre Desplazamiento Forzado, Bogota, Colombia

27. Dane (2005) Censo General 2005 Departamento Administrativo Nacional de Estadística http://www.dane.gov.co. Accessed 15 Jan 2011

28. Achenbach T, Rescorla L (2010) Multicultural Supplement to the Manual for the ASEBA Preschool Forms \& Profiles. University of Vermont, Research Center for Children, Youth \& Families, Burlington

29. Locke CJ, Southwick K, McCloskey LA, Fernandez-Esquer ME (1996) The psychological and medical sequelae of war in Central American refugee mothers and children. Arch Pediatr Adolesc Med 150(8):822-828

30. Goldmann E, Aiello A, Uddin M, Delva J, Koenen K, Gant LM, Galea S (2011) Pervasive exposure to violence and posttraumatic stress disorder in a predominantly African American Urban Community: the Detroit neighborhood health study. J Trauma Stress 24(6):747-751

31. Ainsworth MD (1979) Infant-mother attachment. Am Psychol 34(10):932-937

32. Dekel R, Goldblatt $\mathrm{H}$ (2008) Is there intergenerational transmission of trauma? The case of combat veterans' children. Am J Orthopsychiatry 78(3):281-289. doi:2008-19070-002

33. Scharf M (2007) Long-term effects of trauma: psychosocial functioning of the second and third generation of Holocaust survivors. Dev Psychopathol 19(2):603-622 
34. Betancourt TS, Khan KT (2008) The mental health of children affected by armed conflict: protective processes and pathways to resilience. Int Rev Psychiatry 20(3):317-328

35. Zahr LK (1996) Effects of war on the behavior of Lebanese preschool children: influence of home environment and family functioning. Am J Orthopsychiatry 66(3):401-408

36. Kohrt BA, Jordans MJ, Tol WA, Speckman RA, Maharjan SM, Worthman CM, Komproe IH (2008) Comparison of mental health between former child soldiers and children never conscripted by armed groups in Nepal. JAMA 300(6):691-702
37. Flanders WD, Lin L, Pirkle JL, Caudill SP (1992) Assessing the direction of causality in cross-sectional studies. Am J Epidemiol 135(8):926-935

38. Ministerio de Educación (2010) [Sectorial statistics basic and medium level education; coverage according to state and level] Estadísticas Sectoriales Educación Básica y Media; Cobertura neta por departamento y nivel Ministerio de Educación. http://menweb.mineducacion.gov.co/seguimiento/estadisticas/. Accessed 1 Aug 2011 